05

\title{
Изменение упругих характеристик метастабильной аустенитной стали при циклическом деформировании
}

\author{
(C) А.В. Гончар, В.В. Мишакин, В.А. Клюшников, К.В. Курашкин
}

Институт проблем машиностроения РАН - филиал Федерального государственного бюджетного научного учреждения „Федеральный исследовательский центр Институт прикладной фризики Российской академии наук“ 603024 Нижний Новгород, Россия

e-mail: imndt31@mts-nn.ru

(Поступило в Редакцию 30 марта 2016 г. В окончательной редакции 7 июня 2016 г.)

Исследовано влияние упруго-пластического циклического деформирования на анизотропию упругих свойств метастабильной аустенитной стали 08X18Н10T. Показана возможность определения амплитуды деформации цикла усталостного нагружения акустическим методом путем измерения упругих характеристик материала. Выявлены экспериментальные зависимости, позволяющие провести оценку циклической наработки с помощью ультразвуковых исследований.

DOI: 10.21883/JTF.2017.04.44310.1828

\section{Введение}

Акустические исследования влияния циклического деформирования на состояние метастабильной стали аустенитного класса [1] показали связь фазовых превращений при усталостном разрушении с упругими характеристиками металла, в частности с коэффициентом Пуассона. Выделение в процессе нагружения жесткой упрочняющей фазы мартенсита деформации приводит к изменению упругих свойств всего материала и существенному увеличению плотности энергии пластического деформирования мягкой фазы - аустенита. Это объясняет высокую корреляцию плотности объемной доли жесткой фазы с плотностью микропор, микротрещин, приведенную в [2].

Однако определение объемной доли выделившейся упрочняющей фазы с помощью коэффициента Пуассона не позволяет оценить предысторию нагружения материала. Измерение других свойств акустическим методом, например анизотропии, дает возможность более детально рассмотреть влияние амплитуды нагружения на упругие характеристики металла.

Оценка упругой анизотропии в поликристаллических материалах, которые, как правило, рассматриваются как изотропные, является „тонким“ измерением, что выдвигает соответствующие требования к акустической аппаратуре.

Изделия металлического проката из поликристаллических материалов (листы, уголки, швеллеры и др.) вследствие наличия кристаллографической и морфологической текстур имеют некоторую анизотропию упругих свойств и являются в большинстве случаев ортотропными материалами, т.е. обладают тремя взаимно перпендикулярными плоскостями симметрии, нормальными к осям симметрии $[3,4]$. Для ортотропного материала число независимых упругих постоянных равно девяти, для изотропного материала число независимых констант равняется двум. Они могут определяться акустическим методом при трехстороннем прозвучивании образцов поперечными и продольными объемными волнами при известной плотности материала [4,5]. При одностороннем доступе к изделию можно измерять три модуля упругости.

Для изотропного материала связь коэффициента Пуассона $v$ с модулями упругости: модулем Юнга $E$, сдвига $\mu$, скоростями продольных $V_{l}$ и поперечных $V_{\tau}$ упругих волн, выражается следующим образом [6]:

$$
v=\frac{1}{2}\left(\frac{E}{\mu}-2\right)=\frac{\left(V_{l} / V_{\tau}\right)^{2}-2}{2\left[\left(V_{l} / V_{\tau}\right)^{2}-1\right]} .
$$

Отличие модулей упругости, выделившейся в процессе циклического нагружения фазы мартенсита от модулей матрицы материала, приводит к изменению упругих и акустических характеристик всего сплава.

Основные фазовые превращения в сталях аустенитного класса заключаются в формировании из фазы аустенита $\gamma$ (ГЦК-решетка) двух типов мартенситных фаз: $\alpha^{\prime}$-мартенсита, имеющего в общем случае тетрагональную решетку, полученную в результате искажения ОЦК решетки атомами углерода, и $\varepsilon$-мартенсита, обладающего гексагональной плотноупакованной решеткой (ГПУ) [7-10]. Мартенситные превращения могут происходить следующими способами: $\gamma \rightarrow \varepsilon \rightarrow \alpha^{\prime}$ или $\gamma \rightarrow \alpha^{\prime}[7,8]$. Образование и рост кристаллов мартенсита происходит по сдвиговому механизму в строго определенных направлениях, связанных с направлением действующих напряжений и ориентацией систем скольжения аустенитных зерен стали [11]. При достаточно большой амплитуде нагружения могут быть задействованы дополнительные направления скольжения, и образование кристаллов мартенсита в этих направлениях будет также влиять на анизотропию упругих свойств материала. Необходимо также принимать во внимание, что в результате деформации происходит изменение кристаллографической текстуры [12] исходной фазы $\gamma$-железа. 


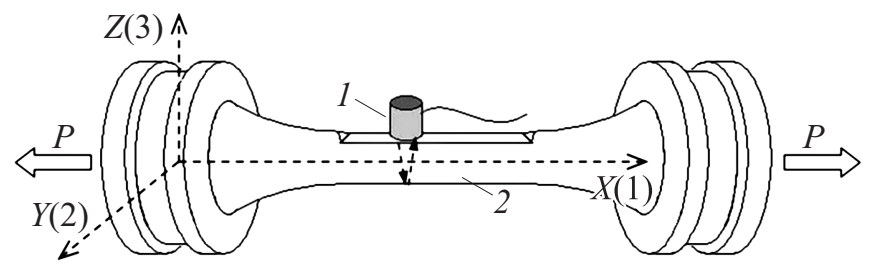

Рис. 1. Схема акустических измерений: $X(1), Y(2), Z(3)-$ оси симметрии образца, 1 - пьезопреобразователь, 2 - образец.

Связь кристаллографической текстуры однофазного ортотропного материала со скоростями распространения объемных упругих волн приведена в $[13,14]$. Теоретическое описание процесса изменения анизотропии в метастабильном сплаве при выделении дополнительных фаз в процессе силового нагружения представляет значительные трудности. Экспериментальное исследование изменения упругих модулей и анизотропии упругих свойств дает дополнительную информацию о процессе усталостного разрушения метастабильных аустенитных сталей.

В любом направлении анизотропного материала могут распространяться три плоские волны - одна продольная и две поперечные [5]. Схема акустических измерений исследуемого ортотропного материала приведена на рис. 1. Одноосное циклическое нагружение силой $P$ направлено вдоль оси $X(1)$, продольные и поперечные волны распространяются вдоль оси $Z(3)$, поляризация поперечных волн может быть направлена как вдоль оси нагружения $X(1)$, так и поперек - вдоль оси $Y(2)$.

Наличие анизотропии упругих свойств приводит к разнице в скоростях поперечных волн, поляризованных вдоль и поперек осей анизотропии (эффект двулучепреломления).

Связь модулей упругости со скоростями продольной $V_{33}$ и поперечными волнами $V_{31}$ и $V_{32}$ [13], распространяющимися вдоль оси $Z$, для ортотропного материала записывается в виде

$$
V_{33}=\sqrt{c_{33} / \rho}, \quad V_{31}=\sqrt{c_{55} / \rho}, \quad V_{32}=\sqrt{c_{44} / \rho},
$$

где $c_{33}, c_{44}, c_{55}$ - модули упругости (матричное обозначение), $\rho$ - плотность материала. Первый индекс в обозначении скоростей соответствует направлению распространения волны, второй - направлению поляризации.

Для описания анизотропии упругих свойств поликристаллических материалов, состоящих из кристаллов с кубической решеткой, в [14] предложено использовать следующую комбинацию скоростей:

$$
A=\frac{V_{31}^{2}-V_{32}^{2}}{\sum_{i=1}^{3} V_{3 i}^{2}}=\frac{1 / \tau_{31}^{2}-1 / \tau_{32}^{2}}{\sum_{i=1}^{3} 1 / \tau_{3 i}^{2}},
$$

где $\tau_{33}-$ время распространения продольных волн, $\tau_{31}, \tau_{32}$ - времена распространения поперечных волн, поляризованных вдоль и поперек оси нагружения соответственно.

Параметр $A$ пропорционален разности модулей упругости $A \sim\left(c_{55}-c_{44}\right)$ и определяется в основном кристаллографической текстурой поликристаллического материала $[13,14]$.

Соотношения модулей $c_{33} / c_{44}$ и $c_{33} / c_{55}$ можно записать в виде

$$
\frac{c_{33}}{c_{44}}=\frac{\left(v_{32}-1\right)}{\left(v_{32}-0.5\right)}=\frac{\tau_{32}^{2}}{\tau_{33}^{2}}, \quad \frac{c_{33}}{c_{55}}=\frac{\left(v_{31}-1\right)}{\left(v_{31}-0.5\right)}=\frac{\tau_{31}^{2}}{\tau_{33}^{2}},
$$

где коэффициенты $v_{31}, v_{32}$ выражаются аналогично (1) через соотношения скоростей

$$
v_{31}=\frac{\left(V_{33} / V_{31}\right)^{2}-2}{2\left[\left(V_{33} / V_{31}\right)^{2}-1\right]}, \quad v_{32}=\frac{\left(V_{33} / V_{32}\right)^{2}-2}{2\left[\left(V_{33} / V_{32}\right)^{2}-1\right]} .
$$

Для изотропного материала $v_{31}=v_{32}=v, c_{44}=c_{55}=$ $=\mu$. Значения коэффициентов $v_{31}$ и $v_{32}$ квазиизотропных материалов, к которым относятся изделия стального проката, могут отличаться на несколько процентов.

Современная аппаратура и методы обработки сигнала позволяют проводить прецизионные измерения времени распространения упругих волн различного типа и поляризации [15]. Поэтому параметры, определяемые с помощью соотношения времен распространения продольных и поперечных волн различной поляризации, обладают существенно меньшей относительной погрешностью, чем, например, скорости распространения упругих волн, для расчета которых необходимо измерение длины акустического пути.

\section{1. Методика проведения эксперимента}

При проведении усталостных испытаний использовались 6 образцов круглого сечения (диаметр рабочей зоны $12 \mathrm{~mm}$ ) типа II (ГОСТ 25.502-79), изготовленных из стали 08X18Н10Т. На каждом образце в рабочей зоне с двух сторон были выточены плоские параллельные друг другу площадки для проведения ультразвуковых измерений (рис. 1). Образцы подвергались регулярному нагружению в области малоцикловой усталости, при котором задавалась амплитуда деформаций цикла $\varepsilon_{a}$. Вид нагружения - растяжение-сжатие, коэффициент асимметрии цикла $R=-1$, режим - жесткий, частота $\sim 3 \mathrm{~Hz}$. Образцы были разделены на 3 пары, каждую из которых испытывали при одной из трех амплитуд деформаций цикла, значения которых составляли 0.33 , 0.56 и $0.77 \%$. Количество циклов нагружения до образования макротрещины $N^{*}$ составляло приблизительно для образцов с $\varepsilon_{a}=0.33 \%-15000$, для $\varepsilon_{a}=0.56 \%$ 1900 , для $\varepsilon_{a}=0.77 \%-500$ циклов. Нагружение каждого образца проводилось поэтапно. Плоско-параллельные площадки размечались на зоны, в которых до испытаний и после каждого этапа нагружения выполнялись ультразвуковые измерения. 
Для измерения времени распространения продольных и поперечных упругих волн использовался эхоимпульсный метод. Центральная частота пьезоэлектрических преобразователей $\sim 5 \mathrm{MHz}$. Диаметр преобразователей $6 \mathrm{~mm}$. Погрешность измерения времени распространения упругих волн 2-3 ns, погрешность измерения $v_{32}$ и $v_{31}$, составляла $7 \cdot 10^{-4}$, параметра $A-5 \cdot 10^{-4}$. Испытания проводились при комнатной температуре.

\section{2. Результаты исследования}

В результате ультразвуковых исследований были определены параметр $A$ и соотношения модулей $c_{33} / c_{44}$, $c_{33} / c_{55}$ до испытаний и после каждого этапа нагружения. Изменение анизотропии упругих свойств $A$ в зависимости от относительного количества циклов нагружения (наработки) $N / N^{*}(N-$ текущее количество циклов, $N^{*}$ — количество циклов до разрушения) приведено на рис. 2. Значение параметра $A$ усреднялось по двум образцам для каждой амплитуды.

Как видно из рис. 2 характер поведения параметра $A$ зависит от значения амплитуды деформации $\varepsilon_{a}$. Можно предположить, что изменение параметра $A$ определяется двумя конкурирующими процессами: изменением кристаллографической текстуры исходной фазы $\gamma$-железа и выделением фазы мартенсита определенной кристалло-

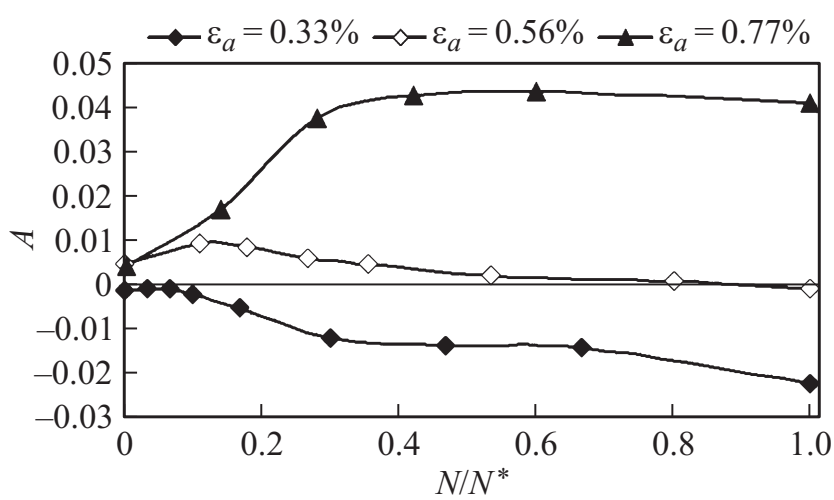

Pис. 2. Зависимость усредненной по всем измеряемым зонам величины акустической анизотропии от величины наработки.
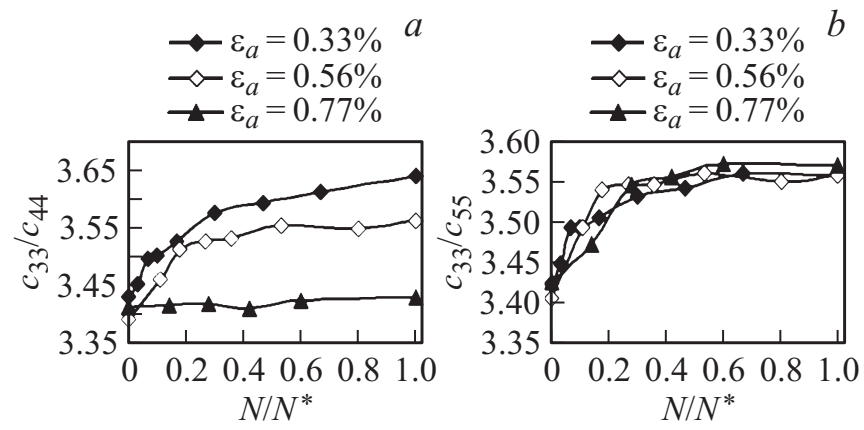

Рис. 3. Влияние наработки на соотношение модулей $c_{33} / c_{44}(a)$ и $c_{33} / c_{55}(b)$.

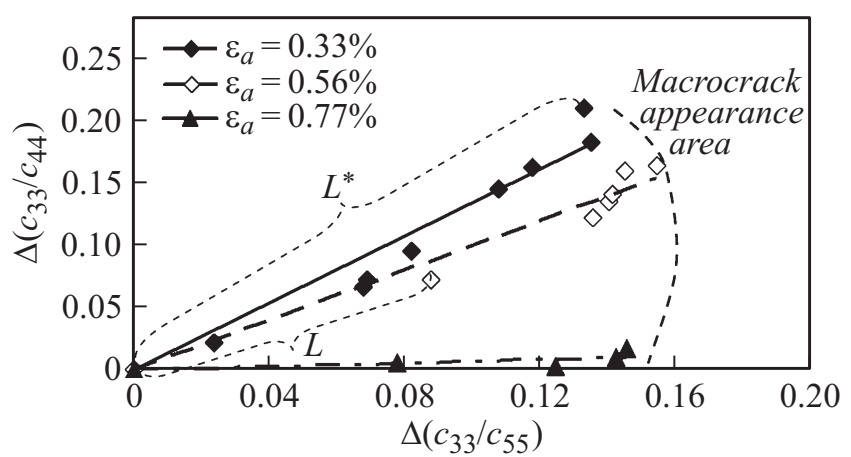

Рис. 4. Зависимость между изменениями $c_{33} / c_{44}$ и $c_{33} / c_{55}$ при циклическом деформировании.

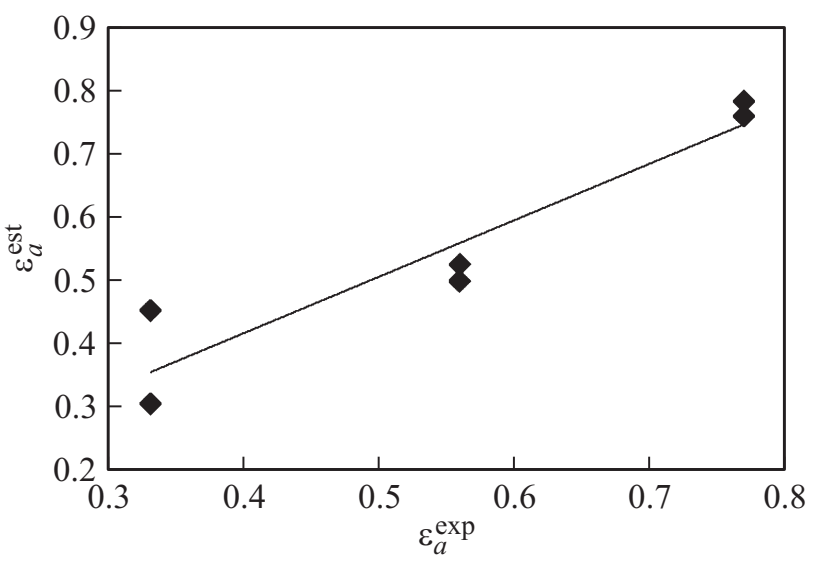

Рис. 5. Корреляционное поле между амплитудой деформации $\varepsilon_{a}$, рассчитанной с помощью акустических измерений, и фактической амплитудой.

графической ориентации. Разница значений параметра $A$ в точке разрушения для амплитуд 0.33 и $0.77 \%$ достигает $\approx 0.06$.

Влияние наработки на соотношение модулей $c_{33} / c_{44}$ и $c_{33} / c_{55}$ приведено на рис. 3 .

Различная интенсивность изменения величин $c_{33} / c_{44}$ и $c_{33} / c_{55}$ также характеризует развитие анизотропии упругих свойств в процессе усталостного разрушения. Результаты эксперимента показали, что соотношение $c_{33} / c_{44}$ чувствительно к амплитуде деформации. Связь $\Delta\left(c_{33} / c_{44}\right)$ с $\Delta\left(c_{33} / c_{55}\right)$ хорошо аппроксимируется линейной зависимостью (рис. 4). Угол наклона этих зависимостей определяется амплитудой деформации цикла $\varepsilon_{a}$. При максимальной амплитуде деформации цикла $\left(\varepsilon_{a}=0.77 \%\right)$ наблюдается минимальное изменение соотношения $c_{33} / c_{44}$.

По-видимому, преимущественная ориентация кристаллов выделившейся фазы зависит от условий нагружения, что отражается на развитии анизотропии упругих свойств всего материала.

Связь тангенса угла наклона $\varphi$ кривых зависимостей $\Delta\left(c_{33} / c_{44}\right)$ и $\Delta\left(c_{33} / c_{55}\right)$ с амплитудой деформации $\varepsilon_{a}$ 


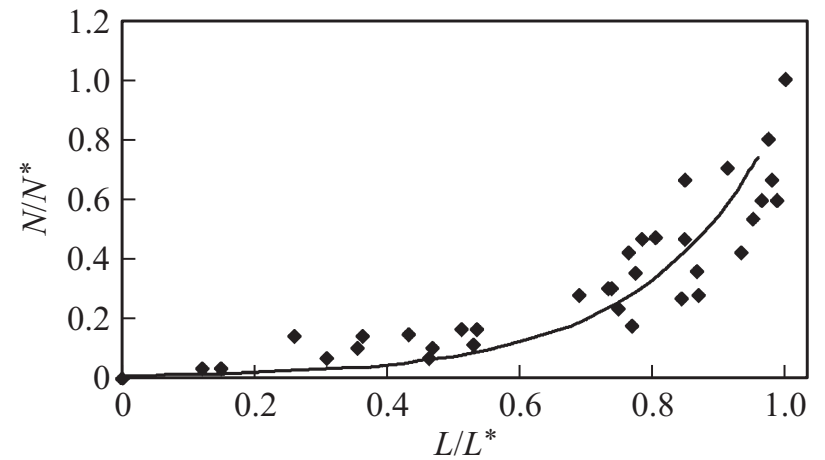

Рис. 6. Связь наработки с относительной длиной $L / L^{*}$.

можно представить полиномом второй степени

$$
\varepsilon_{a}=k_{0}+k_{1} \operatorname{tg} \varphi+k_{2}(\operatorname{tg} \varphi)^{2}
$$

где $k_{0}=0.78, k_{1}=-0.22, k_{2}=-0.06$.

Корреляционное поле между амплитудой деформации $\varepsilon_{a}$, полученной с помощью акустических измерений $\left(\varepsilon_{a}^{\mathrm{est}}\right)$, и фактической амплитудой деформации $\left(\varepsilon_{a}^{\exp }\right)$ для исследуемых образцов, приведено на рис. 5. Коэффициент корреляции составляет 0.94 .

Полученное значение $\varepsilon_{a}$ можно использовать для определения количества циклов до разрушения $N^{*}$, используя, например, соотношение Кофина-Мэнсона [16]

$$
N^{*}=C \varepsilon_{a}^{n}
$$

где $C=182$, и $n=3.99-$ коэффициенты.

Связь циклической наработки с относительной длиной кривых $L / L^{*}$ для всех амплитуд деформации цикла $\varepsilon_{a}$, приведенных на рис. 4, можно аппроксимировать экспоненциальной зависимостью (рис. 6):

$$
\frac{N}{N^{*}}=0.009 e^{4.47 L / L^{*}},
$$

где $L-$ текущее значение длины кривой, соответствующее $N, L^{*}$ - значение длины кривой при разрушении материала, $L^{*}=k_{0 l}+k_{1 l} \varepsilon_{a}+k_{2 l} \varepsilon_{a}^{2}, k_{0 l}=0.005, k_{1 l}=0.07$, $k_{2 l}=-0.08,0 \leq L / L^{*} \leq 1, \varepsilon_{a}<1$.

Данное выражение позволяет оценить наработку при циклическом регулярном режиме нагружения в области малоцикловой усталости при амплитуде деформации $\varepsilon_{a}<1$ метастабильной аустенитной стали 08Х18Н10Т путем определения изменения упругих характеристик акустическим методом.

\section{Заключение}

В результате проведенных исследований показано, что модули упругости и упругая анизотропия метастабильной аустенитной стали являются чувствительными к изменениям в материале в процессе усталостного разрушения.
Характер поведения анизотропии упругих свойств определяется амплитудой деформации и соответственно процессами, связанными предположительно с изменением кристаллографической текстуры исходной фазы аустенита и образованием фазы мартенсита деформации в процессе циклического нагружения.

Выявленные экспериментальные зависимости позволяют провести оценку наработки материала и рассчитать амплитуду деформации цикла по данным акустических измерений.

Исследование выполнено при финансовой поддержке РФФИ в рамках научного проекта № 16-38-60155 мол_а_дк.

\section{Список литературы}

[1] Мишакин В.В., Клюшников В.А., Гончар А.В. // ЖТФ. 2015. Т. 85. Вып. 5. С. 32-36.

[2] Терентьев В.Ф., Колмаков А.Г., Блинов В.М. // Деформация и разрушение материалов. 2007. № 6. С. 2-9.

[3] Теребушко O. Основы теории упругости и пластичности. М.: Наука, 1984. 320 c.

[4] Буссе Г., Солодов И.Ю., Штоссель Р., Шютс Ю. // Акустический журн. 2002. Т. 48. № 1. С. 22-27.

[5] Труэлл Р., Эльбаум Ч., Чик Б. Ультразвуковые методы в физике твердого тела. М.: Мир, 1972. 308 с.

[6] Неразрушающий контроль и диагностика: справочник / Под ред. В.В. Клюева. М.: Машиностроение, 1995. 488 с.

[7] Гольдитейн М.И., Бронфин Б.М., Литвинов В.С. Металлофизика высокопрочных сплавов. М.: Металлургия, 1986. $312 \mathrm{c}$.

[8] Behrens E., Hübner S., Bouguecha A., Knigge J., VogesSchwieger K., Weilandt K. // Adv. Mater. Res. 2010. Vol. 137. P. 1-33.

[9] Гуляев А. Металловедение. М.: Металлургия, 1986. 544 с.

[10] Hedström P. Deformation, Martensitic Phase. Transformation in Stainless Steels // Luleå University of Technology, Department of Applied Physics and Mechanical Engineering, Division of Engineering Materials Sweden, 2007. 160 p.

[11] Новиков И. Теория термической обработки металлов. М.: Металлургия, 1978. 392 с.

[12] Вишняков Я., Бабарэко А., Владимиров С., Эгиз И. Теория образования текстур в металлах и сплавах. М.: Наука, 1979. 345 c.

[13] Sayers C. // Appl. Phys. 1982. Vol. 15. P. 2157-2167.

[14] Allen D., Sayers C. // Ultrasonics. 1984. Vol. 22. P. 179-188.

[15] Курашкин К., Мишакин В. // Заводская лаборатория. Диагностика материалов. 2013. № 4. С. 54-58.

[16] Коллинз Джс. Повреждение материалов в конструкциях. Анализ. Предсказание. Предотвращение. М.: Мир, 1984. $624 \mathrm{c}$. 